\title{
PENGARUH BUDAYA ORGANISASI DAN KEPUASAN KERJA TERHADAP ORGANIZATIONAL CITIZENSHIP BEHAVIOR (OCB) GURU SMP SWASTA KOTA BOGOR
}

\author{
Dian Pintaningdyah*
}

\begin{abstract}
The objective of this research was to research and study the influence of Organization Culture and Job Satisfication toward Organizational Citizenship Behavior $(O C B)$ of private high school teachers in Bogor City. The research was quatitative research with survey method that was analyzed using path analysis. Population target of the research was 200 private high school teachers in Bogor City, West Java Propince. Sampling technique using Random Sampling, that was taking sampling with simple random. Measured the amount of sampling used Slovin formula and the result was 133 respondent. The research shows that the coefficient path value of Organization Culture toward OCB 0,378with tstat of 0,303. Therefore, Organization Culture was directly influence toward OCB. The coefficient path value of Job Satisfication toward OCB 0,361 with tstat 0,280. Therefore, Job Satisfication was directly influence toward $O C B$. The coefficient path value of Organizational Culture toward Job satisfication 0,267 with tstat 0,267. Therefore, Organizational Culture was directly influence toward Job Satisfication.
\end{abstract}

Keywords: organization culture, job satisfication, organizational citizenship behavior

\section{PENDAHULUAN}

Kementerian Pendidikan dan Kebudayaan (Kemendikbud) terus berupaya membumikan nawacita melalui program-program prioritas pemerintah di bidang pendidikan dan kebudayaan. Selama 2 tahun pemerintahan Kabinet Kerja, Kemendikbud meningkatkan angka Indeks Pembangunan Manusia (IPM) sebesar 0,75 poin dari 68,8 pada tahun 2014 menjadi 69,55 pada tahun 2015. Dengan indeks pendidikan meningkat sebesar 0,82 poin dari 60,18 menjadi 61,00 di Tahun 2015. Peningkatan IPM tersebut disebabkan oleh peningkatan rata-rata lama sekolah penduduk usia 25+ dari 7,73 tahun menjadi 7,83 tahun pada tahun 2015 dan peningkatan rata-rata harapan lama sekolah yang meningkat dari 12,39 tahun menjadi 12,55 tahun pada tahun 2015. Salah satu dampak program PPK adalah pergeseran peran kepala sekolah yang lebih menjurus pada bidang manajerial,

${ }^{*}$ Kepala SMP Islam Al Mustarih 
dan guru sebagai inspirator bagi peserta didik. Kepala Sekolah menjadi teladan kepemimpinan dan mendukung ekosistem pendididkan di sekolah. "Dengan prinsip gotong royong, sekolah, masyarakat dan pemangku kepentingan lainnya bekerjasama untuk mewujudkan ekosistem pendidikan yang berkarakter." edupost.id/berita-pendidikan/mendikbud/2016/9/3. diakses tanggal 19 April 2017.

Pendidikan adalah karya bersama yang berlangsung dalam suatu pola kehidupan insani tertentu. Pemahaman mengenai pendidikan mengacu pada konsep yang menggambarkan bahwa pendidikan memiliki sifat dan sasarannya yaitu manusia. Manusia itu sendiri mengandung banyak aspek dan sifatnya yang sangat kompleks.

Pendidikan bukanlah semata-mata merupakan upaya menyiapkan individu untuk dapat menyesuaikan dirinya dengan lingkungan, melainkan lebih diarahkan pada upaya pembentukan dan kesediaan melestarikan lingkungan dalam jalinan yang selaras.

Beberapa permasalahan kadang muncul dalam dunia pendidikan terutama yang menyangkut guru atau tenaga pendidik di sekolah, seperti terjadi di kota Bogor sebagai daerah penelitian peneliti.Permasalahan yang muncul menjelang Ujian Nasional 2017 , dalam kotak suara online yang ditujukan kepada Dinas Pendidikan Kota Bogor pada tanggal 29 Maret 2017 disampaikan oleh Supriyanto," Assalamu'alaikum kepada ketua dinas pendidikan yg terhormat, ada seorang guru yang tidak simpati kepada anak muridnya, karena sianak ini dalam keadaan sakit tidak bisa mengikuti tryout di sekolah, kata guru kalau tidak bisa mengikuti tryout itu dia tidak bisa lulus kayanya, apakah kalau anak sakit bisa mengikuti tryout di rumah, malah gurunya gak pernah nengok, anak murid yang sakit, saya mohon kepada aparat dinas pendidikan untuk menegur seorang guru itu...terima kasih." Kotak surat online/2017/03/29

Menanggapi permasalahan diatas, dalam info Antara News, Jum'at 21 April 2017, Dinas Pendidikan Kota Bogor bekerjasama dengan Universitas Paramadina melaksanakan pendidikan demokrasi bagi 45 guru SMP di Kota Bogor. Walikota Bogor, Bima Arya Sugiarto menyebutkan, "pentingnya pendidikan demokrasi untuk membangkitkan rasa nasionalisme generasi muda Indonesia yang saat ini mulai mengalami degradasi karena pengaruh globalisasi." AntaraNews/2017/04/18.

Disampaikan pula oleh Plt Kepala Dinas Pendidikan Kota Bogor, Fachruddin, "Sifat dan jiwa demokrasi harus dimiliki setiap individu termasuk para tenaga pendidik dalam rangka berbangsa dan bernegara, saling menghargai dan mendengarkan." Menteri Pendidikan dan Kebudayaan (Mendikbud) Muhadjir Effendy di Kantor Kemendikbud, Jakarta, Jum'at (30/12/2016).m.tribunnews.com/ nasional/2016/12/30 (diakses tanggal 19 April 2017).

Pernyataan dan pelaksanaan kegiatan di atas berkaitan dengan kondisi OCB guru di Kota Bogor, Sueb selaku sekretaris pengawas SMP Kota Bogor disampaikan pada tanggal 21 April 2017 di SMPN 5 Kota Bogor bahwa: 
Organizational Citizenship Behavior (OCB) guru SMP swasta di Kota Bogor masih rendah, hal ini dilihat dari berbagai permasalahan yang terjadi di sekolah binaannya, seperti peran guru DPK yang berada di sekolah swasta di daerah Bogor Barat masih kurang, dimana yang aktif dan kreatif adalah guru-guru honorer di sekolah tersebut. Ada juga sekolah yang masih meminta bantuan pengawas untuk menyelesaikan permasalahan siswa di sekolahnya yang seharusnya menjadi tanggung jawab guru-guru di sekolah tersebut. Masih banyaknya guru yang mengajar di dua atau tiga sekolah bahkan ada yang mengajar di empat sekolah dikarenakan mengejar kebutuhan finansialnya. Untuk hal tersebut terjadi di seluruh kecamatan di Kota Bogor. Tidak adanya reward dari sekolah dan Permasalahan tersebut berakibat kurangnya OCB guru terhadap tempatnya bekerja. Para guru itu beranggapan yang bertanggung jawab dalam permasalahan siswa hanyalah pembina kesiswaan dan wali kelasnya saja. Untuk guru yang lain tidak ada urusan ataupun kepentingannya.

Selain dari hasil pengamatan dan laporan dari para kepala sekolah, para pengawas juga mempunyai kewenangan untuk mendata hasil penilaian kinerja para guru di sekolah binaannya. Dalam penilaian kinerja masih terlihat kurangnya peran guru memajukan atau mengembangkan sekolahnya terutama untuk SMP swasta yang jumlah siswanya dibawah 200 siswa. Hal ini dikarenakan kurangnya motivasi para guru, kurangnya penghargaan dari pihak sekolah, gaya kepemimpinan yang monoton, kondisi lingkungan sekolah yang kurang mendukung sehingga tidak munculnya kepuasan kerja dari para guru-guru tersebut dan berakibat pada ketidakperdulian guru akan perkembangan sekolahnya. Keterbatasan anggaran sekolah juga merupakan permasalahan yang membuat para guru berperilaku kurang perduli memajukan sekolahnya. Rubrik Dinas Pendidikan, Sueb. Sekretaris Pengawas SMP Dinas Pendidikan Kota Bogor, 2017/04/21.

Menurut Kadiyo, pengawas SMP Kota Bogor yang disampaikan di SMPN 17 Kota Bogor pada tanggal 21 April 2017, bahwa: OCB guru SMP swasta di Kota Bogor masih kurang dikarenakan kondisi guru-guru SMP swasta bekerja sesuai dengan jam mengajar yang dilaksanakannya, apabila jam mengajarnya dianggap belum mampu memenuhi kebutuhan hidupnya maka mereka akan mencari sekolah lain untuk memenuhi kebutuhan hidupnya. Tidak dipungkiri karena nominal rupiah yang diperoleh dari sekolah yang jumlah siswanya belum dapat memenuhi standar kelayakan kehidupannya di era sekarang ini. Hal ini menyebabkan tenaga, waktu dan pikiran guru-guru tersebut terkuras sehingga tidak terinspirasi untuk membantu mengembangkan sekolahnya.

Selain itu dikarenakan bekerja di beberapa sekolah menyebabkan seorang guru sering terlambat hadir dan menimbulkan tidak efektifnya proses kegiatan belajar mengajar.Untuk sekolah dengan jumlah siswa yang banyak dan memiliki kekuatan dari segi keuangan hal tersebut tidak bermasalah, tapi menjadi masalah bagi sekolah dengan jumlah siswa sedikit (dibawah 200 siswa), satu kondisi guru harus mengajar sesuai mata pelajaran yang menjadi kompetensinya (yang 
diampu) tapi satu kondisi kondisi pendanaan sekolah yang terbatas. Namun ternyata ada satu SMP binaannya di daerah Bogor Selatan yang memiliki jumlah siswa sedikit tapi gurunya tetap berkarya di sekolah tersebut padahal dari Januari 2017 belum digaji. Hal ini terlihat dari keterbukaan dari pihak sekolah, pedekatan yang dilakukan kepala sekolah dan Yayasan sehingga guru-guru merasa memiliki sekolah tersebut. Hal tersebut menunjukkan bahwa peran sebuah lembaga sangat besar dalam pengembangan lembaganya agar tetap bertahan atau berkembang lebih baik. Rubrik Dinas Pendidikan, Kadijo. Sekretaris Pengawas SMP Dinas Pendidikan Kota Bogor, 2017/04/21.

Pernyataan yang disampaikan para pengawas kota Bogor menggambarkan kondisi nyata guru-guru SMP Swasta di Kota Bogor yang mana beberapa masalah muncul disebabkan oleh kondisi guru itu sendiri, pekerjaanya, aturan yang diberlakukan dan lingkungan kerja. Dalam hal ini perlu pembenahan agar para guru tersebut memahami tugasnya dan merasakan kenyamanan dalam pekerjaanya. Beberapa hal tersebut diantaranya: gaji, kenyamanan lingkungan sekolah, budaya organisasi, kepemimpinan, kepuasan kerja dan sebagainya. Hal-hal yang disampaikan dapat mempengaruhi OCB guru Swasta terhadap organisasinya

Secara konseptual, OCB didefinisikan secara beragam. Organ dikutip Luthans (2011:149) mendefinisikan OCB sebagai,"individual behavior that is dicretionary, not directly or explicitly recognized by the formal reward system, and that in the agregate promotes the effective functioning of the organization." OCB sebagai perilaku individu, kebebasan individu, tidak secara langsung ataupun secara implisit mendapat penghargaan dari sistem imbalan formal dansecara keseluruhan mendorong keefektifan fungsi- fungsi organisasi.

John R.Schermerhorn (2010:73) mendefinisikan," organization citizenship behavior are the extras people do to go the extra mile in their work". Organization citizienship adalah kemauan untuk menjalankan pekerjaan di luar kewajibannya. Seseorang yang memilki organization Citizenship yang tinggi akan melakukan segala sesuatu untuk organisasinya.

Sedangkan Rea Andrea (2008:126) mendefinisikan organization citizenship sebagai, "behavior on be helf of the organizational that go beyond normal job ekspectation, and which may even serve a large societal purpose."Organization citizenship adalah perilaku yang menjadi bagian dari organisasi sebagai bentuk pekerjaan di luar ekspektasi normal dan dapat memberikan pelayanan lebih untuk mencapai tujuan organisasi.

Sementara Colquitt, LePine dan Wesson (2103:39) mendefinisikan, "citizenship behavior is defined as voluntary employee activities that may or may not be rewardes but contribute to the organizational by improving the overall quality of setting in which work take place,".Perilaku citizenship adalah kegiatan pegawai yang dapat atau tidak dapat penilaian tetapi memberikan kontribusi untuk organisasi dengan memberikan kualitas terbaik dalam bekerja. 
Cambell dan Nelson (2011:184) mendefinisikan bahwa:OCB is enchanced most throught employee involvement programs airmed at engaging employess in the work organization rather throught employee involvement in employment desicions in operations.OCB adalah berpikir program keterlibatan karyawan ditingkatkan paling dituju untuk melibatkan karyawan dalan organisasi kerja dari pada melalui keterlibatan karyawan dalam keputusan kerja.

Selanjutnya McShane dan Von Glinow (2010:17) mendefinisikan, “Organization Citizenship Behavior (OCBs) is various forms of coopeartion and helpfulness to others that support the organization, social and psychological context". OCB merupakan berbagai bentuk kerja sama dan menolong orang lain yang mendukung organisasi sosial dan konteks psikologi.

John R. Schermerhorn (2010:12) mengatakan bahwa budaya organisasi," $a$ shared set of beliefs and values within an organization". Budaya organisasi atau budaya perusahaan adalah suatu sistem dari tindakan, nilai dan keyakinan yang dibangun dalam suatu organisasi.

Menurut Colquitt, LePine \& Wesson (2013:558)," There are three major components to any organization's culture: observable artifacts, espoused values and basic underlying assumptions". Ada tiga komponen utama untuk beberapa budaya organisasi yaitu: observasi nilai sejarah, nilai - nilai/norma yang ada dan asumsiasumsi yang mendasar.

Glinow (2010:416) mendefinisikan:Organizational culture consist of the values and assumptions shared within an organization. It defines what is important and unimpotant in the company and consequently, direct everyone in the organization toward the rigtht way of doing things.Budaya organisasi terdiri dari nilai-nilai dan asumsi bersama dalam sebuah organisasi. Mendefinisikan apa yang penting dan tidak penting dalam perusahaan dan akibatnya mengarahkan semua orang di organisasi terhadap cara yang benar dalam melakukan sesuatu.

Stephen P. Robbins dan Mary Coulter (2012:82) mendefinisikan budaya Organisasi:"How employes learn culture, employees learn an organizatios' culture in a number of ways. The organization regarding the rules, norms and value that shape the attitudes and behavior of it employees". Budaya organisasi sebagai pengetahuan sosial bersama dalamsebuah organisasi mengenal aturan, norma-norma, nila-nilai yang membentuk sikap dan perilaku.

Definisi yang hampir serupa dikemukakan oleh McShane dan Von menurut Angelo Kinicki and Brian Williams (2011:236), mendefinisikan budaya organisasi sebagai berikut," culture is transmitted to employees in several ways, most often throught such devices as symbols, stories, heroes, rites and rituals". Budaya disebarkan kepada karyawandalam beberapa cara yang paling sering melalui perangkat seperti simbol, cerita, pahlawan, upacara dan ritual.

Kreitner dan Kinicki (2011:269) memberikan definisi tentang budaya kerja atau budaya organisasi sebagai berikut: "organizational culture is the set of shared, taken-forgranted implicit assumption that a group holds and that determines how it perceives, thinks 
about, and reacts to its various environments". Budaya organisasi adalah seperangkat bersama (norma-norma organisasi), dengan asumsi bahwa kelompok mematuhinya dan hal tersebut menentukan bagaimana itu dirasakan, dipikirkan, dan beraksi dalam berbagai lingkungan

Wagner \& Hollenbeck (2010:106) mengungkapkan bahwa,"job satisfaction is a pleasurable feeling that results from the perception that one's job fulfills or allows for the fulfillment of one's important job values."Kepuasan kerja merupakan perasaan yang menyenangkan yang dihasilkan dari persepsi bahwa sebuah pekerjaan memenuhi atau diperkenankan untuk memenuhi nilai suatu pekerjaan yang penting.

Menurut Robbins \& Timothy (2017:116), "job satisfication, which describes a positive feeling about a job, resulting from an evaluation of its characteristics". Kepuasan kerja menggambarkan perasaan positif tentang pekerjaan, hasil dari evaluasi karakteristiknya, seperti yang diungkapkan oleh Kreitner \& Kinicki (2011:170)," job satisfication is an affective or emotional response toward various facets of one's $j o b^{\prime \prime}$.Kepuasan kerja merupakan respon afektif atau emosional terhadap berbagai aspek pekerjaan seseorang. Hal ini diungkapkanpula oleh George \& Jones (2010:71), "job satisfication is the collection of feelings and beliefs that people have about their current jobs".Kepuasan kerja adalah kumpulan perasaan dan keyakinan bahwa orang memiliki tentang pekerjaan mereka saat ini. Kepuasan kerja yang dirasakan oleh para karyawan bukanlah sesuatu yang bersifat tiba-tiba, tetapi merupakan hasil penilaian terhadap karakteristik kerja yang diterima, lingkungan kerja, dan perasaan dalam bekerja.

McShane dan Von Glinow (2010:108) menyatakan, "job satisfaction is a person's evaluation of his or her job and work context." Kepuasan kerja adalah penilaian seseorang terhadap pekerjaan dan kondisi kerja. Parapekerjayang puas memberikanpenilaianyang baik tentang pekerjaan mereka berdasarkan pengamatan dan perasaan. Contohnya, pekerja bisa menyukai pekerjaan rekan kerjanya tetapi tidak bisa begitu puas dengan beban kerjanya.

Menurut Schemerhorn (2012:62) dkk., "job satisfaction is the degree to which an individual feels positive or negative abaout a job." Kepuasan kerja adalah tingkat dimana seorang individu merasa positif atau negatif tentang pekerjaan.

Perasaan kepuasankerja yang positif maupun negatif yang dialami karyawan merupakan masalah yang kompleks, karena berasal dari berbagai hal yang berhubungan dengan pekerjaan itu sendiri.Jason A.Colquitt, Jeffery A. LePine dan Michael J.Wesson (2013:105) menyebutkan:Job satisfications defined as a pleasurable emotional state resulting from the appraisal of one's job or job experiences the other words, It represents how you feel about your job and what you think about your job. Employees with high job satisfication experience positive feelings where they think about their duties or take pact as task activities. Employees with low job satisfication experience negative feelings when they think about duties or take part in their task activities.Ini berarti menurut Colquitt, LePine, dan Wesson, kepuasan kerja adalahkeadaan emosional yang menyenangkan yang dihasilkan dari penilaian pekerjaan atau pengalaman kerja. Dengan kata lain, 
kepuasan kerja merupakan gambaran bagaimana perasaan seseorang tentang pekerjaannya sendiridan apa yang dia pikirkan tentang pekerjaannya. Para karyawan dengan kepuasan kerja tinggi mengalami perasaan positif ketika mereka berfikir tentang tugas-tugas mereka mengambil bagian dalam kegiatan tugas mereka.

\section{METODE}

Penelitian ini dilakukan di 20 SMP Swasta di wilayah Kota Bogor, Provinsi Jawa Barat dengan jumlah guru mata pelajaran Ujian Nasional(UN) sebanyak 200 orang. Metode yang digunakan dalam penelitian ini adalah survey dengan menggunakan teknik kausal. Populasi target dalam penelitian ini adalah 200 guru mata pelajaran UN SMP Swasta di Kota Bogor, Provinsi Jawa Barat. Data yang dikumpulkan dalam penelitian dijaring melalui kuesioner yang berupa skala penilaian (rating scale) dengan sebaran skor antara 1 sampai dengan 5.

Setelah dilakukan analisis deskriptif dilanjutkan dengan uji persyaratan analisis berupa uji normalitas, uji linearitas data dan keberartian regresi, dilakukan uji hipotesis dengan menggunakan teknik analisis jalur (path analysis).

\section{HASIL DAN PEMBAHASAN Budaya Organisasi dan OCB}

Dari hasil pengujian hipotesis pertama dapat disimpulkan bahwa terdapat pengaruh langsung positif budaya organisasi terhadap OCB dengan nilai koefisien korelasi sebesar 0,378 dan nilai koefisien jalur sebesar 0,303. Ini memberikan makna budaya organisasi berpengaruh langsung positif terhadap OCB.

Hasil penelitian ini senada dengan pendapat beberapa ahli diantaranya menurut Scheremerhorn (2012:9), organizational culture-the shared beliefs and values that inluence the behavior of organizational members." Satu hal yang secara kontekstual besar pengaruhnya terhadap Organizational Behavior adalah budaya organisasi, keyakinan dan nilai yang mempengaruhi perilaku dari anggota organisasi.

Hampir senada disampaikan John M.Ivancevich, Robert Konopaske and Michael T. Metteson (2011:40), since organizational culture involves shared expectations, values and attitudes, it exerts influence in individual, groups and organizational processes. For example, members are infulenced to be good citizens and to go along. Budaya organisasi melibatkan harapan bersama, nilai-nilai dan sikap, maka hal tersebut mempengaruhi individu kelompok dan proses organisasi. Sebagai contoh, anggota organisasi dipengaruhi untuk menjadi karyawan yang baik dan mengikuti segala aturan yang ada.

Menurut Colquitt, LePine \& Wesson (2013:535): "organizational culture as the shared social knowledge within an organization regarding the riles, norms and values that shape the attitudes and behaviors of its employees."Budaya organisasi adalah sebuah 
bentuk pengetahuan sosial dalam suatu organisasi dengan memandang aturanaturan, norma dan nilai-nilai yang membentuk kecakapan dan perilaku anggotanya.

Budaya organisasi di sekolah terdiri dari nilai-nilai yang terdapat dalam anggotanya, yaitu kepala sekolah, guru dan karyawan yang kemudian akan berpengaruh terhadap lingkungan kerja. Budaya organisasi yang menciptakan lingkungan kerja sesuai dengan harapan dan keinginan anggota organisasi akan mempengaruhi motivasi anggota organisasi.

Seseorang yang termotivasi akan berusaha untuk bekerja lebih baik dan menghasilkan pekerjaan yang terbaik bagi dirinya dan organisasinya. OCB.

Dengan demikian budaya organisasi berpengaruh langsung positif terhadap

\section{Kepuasan Kerja dan OCB}

Dari hasil pengujian hipotesis kedua dapat disimpukan bahwa terdapat pengaruh langsung positif kepuasan kerja terhadap OCB dengan nilai koefisien korelasi sebesar 0,361 dan nilai koefisien jalur sebesar 0,280. Ini memberikan makna kepuasan kerja berpengaruh langsung positif terhadap OCB.

Hasil penelitian ini senada dengan pendapat beberapa ahli di antaranya Colquitt, LePine dan Wesson (2013:116) sebagai berikut," satisfied employees engage in more frequent "extra mile" behaviors to help their co-workers and their organization." Karyawan yang puas terlibat dalam perilaku jauh lebih baik yang lebih sering untuk menolong rekan kerja dan organisasi mereka.

Berkaitan hal tersebut George and Jones (2012:84) menyatakan : "It seems logical to assumse job satisfication should be a major determinant of an employee's organizational citizenship Behavior (OCB). Satisfied employees would seem more likely to talk positively about the organization, help others, and go beyond the normla expectations in their job, perhaps because they want to reciprocate their positive experiences. Consistent with this thinking, evidences suggest job satisfication is moderately correlated with OCBs", people who are more satisfied with their jobs are more likely to engage in OCBs. Nampaknya logika untuk mengasumsikan kepuasan kerja seharusnya menjadi penentu yang sangat penting dari OCB. Karyawan yang merasa puas bekerja akan terlihat lebih positif untuk berbicara terkait organisasinya, saling menolong dan memberikan lebih dari harapan, mungkin dikarenakan mereka menginginkan balasan atas pengalamanpengalaman positifnya. Konsisten dengan penilaian tadi bahwa hasil penelitian menunjukkan kepuasan kerja berhubungan erat dengan OCB. Sesorang lebih puas dengan pekerjaannya akan lebih merasa terikat dengan OCB. Balas jasa atas kepuasan kerja yang didapat karyawan akan membangkitkan perasaan positif karyawan. Tentunya hal ini akan meningkatkan kreatifitas karyawan, penyelesaian masalah, pengambilan keputusan, hubungan dengan rekan kerja dan masyarakat luar organisasi, secara alamiah dan spontan menolong tanpa memandang apa , siapa dan cenderung berusaha untuk melakukan sesuatu yang dapat melestarikan dan 
mengembangkan organisasi atau perusahaan lebih baik,seperti mencegah perilaku yang merugikan perusahaan.

Fred Luthans (2011:149) mengungkapkan pengaruh kepuasan kerja terhadap OCB dalam bagian salah satu prinsip perilaku organisasi dalam bukunya, yaitu ," the attudinal foundation indicates that employees engage in OCBs in order to reciprocate the actions of their organizations. Motivational dimensions, Job satisfication, and organizational commitment, cearly relate to OCBs."Dasar yang menunjukkan keterikatan karyawan di OCB dalam upaya untuk membalas kegiatan organisasinya. Dimensi motivasi, kepuasan kerja dan komitmen organisasi jelas terkait dengan OCB

Perilaku OCB, walaupun secara kuantitas tidak berpengaruh pada hasil imbalan yang diterima pegawai karena memang tidak tercantum dalam prosedur distribusi imbalan yang diterima karyawan, namun hal itu sangat berpengaruh pada kinerja, komitemen dan perilaku pegawai diluar organisasi atau diluar kondisi kerjanya seperti menjaga nama baik organisasi, memperbaiki citra organisasi dan menjalin hubungan baik dengan masyarakat sekitar organisasi sebagai buah hasil perlakuan yang diterima pegawai bahwa mereka diperlakukan dengan baik oleh organisasi dan menimbulkan kepuasan tersendiri bagi pegawai bahwa mereka diperlakukan dengan baik oleh organisasinya, hal ini menimbulkan kepuasan tersendiri bagi pegawai.

Logika tersebut sesuai dengan pendapat Robbins dan Judge (2012:124) yang menyatakan:"it seems logical to assums job satisfication should be a major determinat of an employes's organizational citizeship behavior (OCB). Satisfied employee would seem more likely to talk positively about the organization, help others and go beyond the normal expectations in their job."Patut dikatakan masuk akal untuk menganggap bahwa kepuasan kerja bisa menjadi faktor utama yang menentukan OCB seorang pegawai. Pegawai yang puas akan terlihat cara bicaranya yang bagus tentang organisasinya, menolong orang lain dan berperilaku jauh lebih baik di atas harapan kerja mereka. Mereka anggap ini adalah 'panggilan' tugas karena mereka ingin balas jasa berkaitan pengalaman positif mereka atas perlakuan organisasinya. Balas jasa mengenai kepuasan yang dialami pegawai tentulah atas anggapan keadilan, dimana jika mereka menolong rekan mereka dan berperilaku lebih baik dari yang diharapkan itu karena rekan sesama mereka mendukung mereka juga. Begitu pula jika pegawai tidak merasakan atasan mereka, prosedur organisasi, atau kebijakan upah terasa adil, kepuasan kerja mereka terlihat menurun drastis dan tentu saja hal ini akan berakibat mereka berperilaku negatif.

Tentu saja OCB merupakan hal yang tidak bisa dianggap tidak penting lagi, dimana pada selanjutnya OCB akan mempengaruhi kinerja organisasi dengan mendukung kegiatan kerja secara terus menerus dan mempengaruhi penilaian kinerja. Para pegawai yang berperilaku OCB seperti menolong orang lain atau memberikan ide-ide membangun menerima penilaian kinerja yang jauh lebih baik. Dengan pengaruh lain, para manajer berusaha terus mencari cara dan program yang dapat meningkatkan kepuasan kerja. 
OCB.

Dengan demikian kepuasan kerja berpengaruh langsung positif terhadap

\section{Pengaruh Budaya Organisasi terhadap Kepuasan Kerja}

Dari hasil pengujian hipotesis ketiga dapat disimpulkan bahwa terdapat pengaruh langsung positif budaya organisasi terhadap kepuasan kerja dengan nilai koefisien korelasi sebesar 0,267 dan nilai koefisien jalur sebesar 0,267. Ini memberikan makna budaya organisasi berpengaruh langsung positif terhadap kepuasan kerja.

Hasil penelitian ini senada dengan pendapat beberapa ahli di antaranya Stephen P. Robbins (2015:521) berpendapat," this overall perception becomes, in effect, the organization's culture or personality and affects employee performance and satisfaction, with stronger cultures having grater impact". Karyawan membentuk persepsi subjektif terhadap organisasi berdasarkan pada faktor-faktor persepsi keseluruhan yang menjadi dasaranya adalah budaya organisasi atau kepribadian yang dapat mempengaruhi kinerja karyawan dan kepuasan kerja. Dengan budaya yang kuat memiliki dampak yang lebih besar. Menurut Rae Andrea (2008:128) ada pengaruh antara budaya organisasi dengan kepuasan kerja, "job satisfication is a collection of attitudes about the various parts of job. It can be measured simply by asking a person, "Overall, how satisfied are you with your job?" Kepuasan kerja merupakan sekumpulan sikap dari beberapa bagian suatu pekerjaan. Hal ini dapat diuraikan secara sederhana dengan bertanya pada karyawan, secara keseluruhan bagaimana tingkat kepuasan anda.

Sedangkan menurut James L. Gibson (2012:104), “job satisfaction is an atttude that individuals have about their jobs. It results form their perception of their jobs, based on factors on the work environment work group affiation,working conditions and fringe benefit". Kepuasan kerja adalah sikap seseorang tentang pekerjaannya yang didasari oleh faktor lingkungan kerja, keamanan kerja, kondisi kerja dan pendapatannya.

Pendapat yang hampir serupa dikatakan oleh E. A Locke dalam bukunya Steven L.Mc Shane and Mary Ann Von Glinov (2010:108) mengatakan bahwa, "job satisfaction a person evaluation of his her job and work context, is probably the most studied attitude in organizational behavior". Kepuasan kerja seseorang adalah evaluasi diri dari pekerjaaannya dan konteks kerja, mungkin sikap yang paling banyak dirasakan dalam budaya organisasi.

Keyakinan, nilai dan norma tersebut yang akhirnya dapat mempengaruhi kepuasan kerja melalui perubahan sikap dan perilaku guru untuk bekerja lebih baik lagi atau sebaliknya dapat terjadi ketidakpuasan kerja, karena budaya organisasi yang terbentuk ternyata tidak sesuai dengan harapan guru, seperti: tidak adanya perhatian atas prestasi, malas atau rajin tidak berpengaruh apa-apa. Tidak terciptanya hubungan harmonis antara sesama guru dan karyawan lainnya.

Budaya organisasi yang mendukung tercapainya tujuan organisasi, seperti norma, aturan atau peraturan yang berlaku, simbol dan nilai-nlai dan 
bahasa.Dengan demikian budaya organisasi berpengaruh langsung positif terhadap kepuasan kerja.

\section{DAFTAR RUJUKAN}

Andre, Rea. Organization Behavior, An Introduction to your live in organizational Pearson Prentice Hall, 2008.

Colcuitt A.Jason, Jefeery A. LiPe and Michaell J. Wesson.Organizational Behavior: improving performance and commitment in the workplace. New York: Mc Graw Hill. 2013.

Colquitt, LePine and Wesson, Organizational Behavior: Improving Performance and Commitment in the Workplace, 4 th Edition. London: Mc Graw, 2013.

edupost.id/berita-pendidikan/mendikbud/2016/9/3 (diakses tanggal 19 April 2017)

George. M. Jennifer, Gareth. R. Jones. Interstanding and Managing Organizational Behavior. London: Pearson, 2010.

Gibson, James L. John M. Ivancevich, James H. Donnelly, Robert Konopaske, Organizations Behavior,Structure,Processes. (New York: Mc GrawHill, 2012), h.104

Ivancevich M. John, Robert Konospake. Matterson Organizational Behavior and Management. NewYork: McGraw-Hill. 2011.

Kinicki Angelo. Brian Williams. Management a Practical Introduction. NewYork: McGraw-Hill, 2011.

Luthans, Fred. Organizational Behavior, An Evidence-Based Approach, Twelfth Edition, McGraw- Hill, 2011.

McShane and Von Glinow, Organization Behavior, Fitth Edition. United States: McGraw Hill, 2010.

Menteri Pendidikan dan Kebudayaan (Mendikbud) Muhadjir Effendy di Kantor Kemendikbud, Jakarta, Jum'at (30/12/2016).m.tribunnews.com/nasional/ 2016/12/30 (diakses tanggal 19 April 2017)

Quick James Campbell and Debra L.Nelson, Principles of Organization Behavior, 7 th Edition. New York: Mc Graw Hill, 2011.

Robbins, P. Stephen, Timothy A. Judge. Organizational Behavior. London: Pearson Education Limities, 2012.

Robbins, Stephen P. \& Timothy A. Judge, Organizational Behavior Seventeeth Edition. Pearson Education Limites , 2017. 
Rubrik Dinas Pendidikan, Sueb. Sekretaris Pengawas SMP Dinas Pendidikan Kota Bogor, 2017/04/21

Schermerhorn, et.al, Organizational Behavior 12 th Ed. New Jersey: John Wlilley and Sons, 2012.

Schermerhorn, John R. James G.Hunt, Richard N.Osborn dan May Uhl-Bien, Organizational Behavior 11/e edition. United States: John Willey and Son, 2010.

Schermerhorn, John R. Organizational Behavior, 11th edition. United States: John Wiley \& Son, Inc 2010.

Stephen, Robbins, P. Mary Coulter. Management. New York: Pearson, 2012

Wagner III, John A. \& John R.Hollenbeck, Organizational Behavior. New York: Routledge,2010. 